\title{
Tejiendo un modelo de innovación intercultural
}

\author{
Weaving a model of intercultural innovation
}

Víctor Ronald Zúniga Morales'

\section{Resumen}

Este trabajo ha analizado de manera sucinta la innovación desde la experiencia de la URACCAN a partir del programa doctoral en estudios interculturales. Se trata de una investigación cualitativa explicativa desde una perspectiva hermenéutica al analizar textos, documentos, reportajes, artículos, entrevistas con informantes clave. Los resultados orientan estar ante un contexto cambiante complejo, pero de oportunidades; las universidades son el motor transformador de las sociedades y la interculturalidad puede ser un medio a tales fines; en un mundo tecno científico, la innovación ha sido estudiada desde modelos lineales con conocimientos científicos y tecnológicos. Por tanto, se sugiere profundizar en la innovación intercultural que, considere la diversidad cultural desde el pluralismo epistemológico.

Palabras clave: Colaboración; desarrollo; educación superior; innovación intercultural; URACCAN.

\section{Abstract}

This work has succinctly analyzed innovation from URACCAN's experience from the doctoral program in intercultural studies. It is an explanatory qualitative research from a hermeneutical perspective when analyzing texts, documents, reports, articles, interviews with key informants. The results lead us to a complex changing context, but with opportunities; Universities are the transforming engine of societies and interculturality can be a means to such purposes; In a techno-scientific world, innovation has been studied from linear models with scientific and technological knowledge. Therefore, it is suggested to deepen intercultural innovation that considers cultural diversity from epistemological pluralism.

Keywords: Collaboration; Development; Higher Education; Intercultural Innovation; URACCAN

\section{Introducción}

En un mundo complejo y cambiante en el avance científico y técnico, la innovación tecnológica se posesiona en el centro de la economía desde un enfoque lineal hegemónico caracterizado por la exclusión de otros tipos de conocimientos. Este trabajo analiza de manera suscinta la innovación desde la experiencia de la Universidad de las Regiones Autónomas de la Costa Caribe Nicaragüense (URACCAN), está organizado en cinco secciones: (i) Cambios en los enfoques del "desarrollo" y sus implicaciones; (ii) Panorama general sobre las constituciones, educación superior y acceso de pueblos indígenas en Latinoamérica; (iii) La colaboración intercultural y propuestas innovadoras desde los pueblos indígenas; (iv) Innovación desde un enfoque intercultural que orienta reconocer conocimientos científicos, tecnológicos, locales, tradicionales, autóctonos teniendo como referente la experiencia de la URACCAN y finalmente las conclusiones que orientan la urgencia de profundizar en el estudio de un nuevo modelo de innovación intercultural que considere la diversidad cultural.

\footnotetext{
1 Estudiante del Doctorado en Estudios Interculturales. Director de Innovación y Emprendimiento de la Universidad de las Regiones Autónomas de la Costa Caribe Nicaragüense (URACCAN). Email: victor.zuniga@uraccan.edu.ni https://orcid.org/0000-0002-4063-2219
}

Recibido: 05/03/2020 - Aprobado: 29/09/2020 


\section{Desarrollo}

A lo largo de las últimas décadas la economía del desarrollo y las concepciones del desarrollo entendida como el análisis de las condiciones capaces de favorecer el progreso y el bienestar humano han entrado en fuertes cuestionamiento y crisis. Esta crisis global también ha influido en muchos aspectos del mundo actual entre ellas las Filosofías de la Ciencias que a su vez repercute directamente en los sistemas educativos que imperan en Latinoamérica. Es notorio escuchar en diversos eventos el cómo las ciencias sociales han demostrado una incapacidad para enfrentar estos desafíos y poder integrar en el debate algunos enfoques que han ido surgiendo recientemente, podríamos mencionar a la interculturalidad, desarrollo con identidad o buen vivir de los pueblos.

\section{La modernización el surgimiento del "subdesarrollo"}

Si damos un vistazo rápido a la línea del tiempo vemos que la famosa "Economía del Desarrollo" surge a mediados del siglo XX una vez superada la crisis del período de las ya conocidas guerras mundiales, esta nueva perspectiva planteó el crecimiento económico, expresado como la variación del Producto Interno Bruto (PIB)/hab a lo largo del tiempo, hasta el punto de que algún autor, caso de Galbraith (1984) llegaría agudamente a señalar que:

No hay ninguna otra estadística con una autoridad más convincente. En este contexto el desarrollo comenzó a ser algo medible, cuantificable, a través del crecimiento económico, en este mismo contexto un buen número de países habían accedido a su independencia y se enfrentaban al reto del desarrollo en el marco de un nuevo modelo de relaciones norte-sur, de esta manera nacían dos categorías distintas de países: desarrollados y subdesarrollados.

\section{Desarrollo de la Modernización "surgimiento del mal desarrollo"}

No habrían pasados muchos años (finales de los sesenta y principios de los setenta) donde se suponía el desarrollo de la modernidad cuando comenzaron las críticas hacia el crecimiento económico para superar el subdesarrollo y generar desarrollo entendido como el incremento del bienestar de las personas. Unceta (2009), plantea cuatro problemas que indican la desilusión del modernismo, un primer campo de críticas fue el relativo a la pobreza y la desigualdad, un segundo campo fue el deterioro del ambiente y de los recursos naturales (surge el concepto de ecodesarrollo), el tercer gran problema fue no haber avanzado en términos de equidad de género y la cuarta disfunción fue la no correspondencia entre el crecimiento económico de un lado y el respeto de la libertad y los derechos humanos.

Estos planteamientos eran la evidencia que el desarrollo (Modernidad), tal como se había planteado, habría provocado mayor empobrecimiento, perdida de identidades y de recursos naturales, restricción de derechos humanos y generar nuevos desequilibrios y desigualdades. El Modelo había fracasado y había generado un sistema mundial basado en asimetrías entre unas y otras zonas del planeta por supuesto con mayor poder a los países "desarrollados". La idea del mal desarrollo vendría así a expresar un fracaso global. (Escobar, 2005).

La evidencia del creciente descontento con el desarrollo en distintos lugares del tercer mundo fue lo que dio origen al postdesarrollo. Para algunos esto significó (i) El desarrollo no tomaría lugar únicamente bajo la mirada de Occidente; (ii) Revalorización de las culturas vernáculas, la necesidad de depender menos de los conocimientos de expertos y más de los intentos de la gente común de construir mundos más humanos, así como cultural y ecológicamente sostenibles, (iii) Los movimientos sociales y movilizaciones de base, (iv) Dejar el eurocentrismo, (v) No es un proceso histórico es una nueva visión del desarrollo.

De Sousa (2002), su planteamiento parece coincidir con los proponentes del post-desarrollo: "Estamos trascendiendo el paradigma de la modernidad en dos sentidos: epistemológica y sociopolíticamente". [...]" "la globalización no es la última etapa de la modernidad capitalista, sino el comienzo de algo nuevo". 
El proceso de repensar radicalmente el desarrollo podría abrir las puertas a poderosas posibilidades para enfrentar las crisis económica, ambiental y cultural, por tanto se crea una mayor consciencia de la necesidad de un cambio significativo de modelo; llama a reconstituir el mundo desde la diversidad y la diferencia, desde abajo. ¿Será el buen vivir una de esas posibilidades?

\section{¿Buen vivir realidad o utopía? ¿Qué pasa con el sistema occidental?}

El sistema occidental se acaba, se observan cambios políticos, sociales, económicos y culturales que demuestran que el actual sistema ya no es vigente; Sousa Santos (2002) plantea la incapacidad de pensar más allá de dar soluciones modernas a los problemas modernos.

Es importante destacar que, en las sociedades indígenas no existe el concepto de desarrollo, tampoco la concepción tradicional de pobreza asociada a la carencia de bienes materiales o de riqueza vinculada a su abundancia, esto no es lo único determinante; hay otros valores en juego como el conocimiento, el reconocimiento social y cultural, los códigos de conductas éticas e incluso espirituales en la relación con la sociedad y la naturaleza, valores humanos, visión de futuro, entre otros. El buen vivir constituye una categoría central de la filosofía de vida de las sociedades indígenas (Acosta, 2008).

Pero en el contexto actual, entendido como un momento de transición no se debe de tratar sólo de enunciar al buen vivir como un conjunto de valores, hay que empezar a buscar las formas en que se empiece a convertir en una fuente para resolver los problemas que la modernidad no ha podido resolver, esto nos conlleva a preguntarnos no sólo ¿Qué es? Sino el ¿Cómo lo hacemos?

Si partimos que el post-desarrollo entre uno de sus planteamientos es reconocer las culturas y los distintos movimientos sociales planteados en el acápite anterior, deberíamos considerar implementar verdaderos "Diálogos de saberes con los pueblos" porque son sus voces las que se están escuchando desde su propia experiencia, desde su propia vivencia en la comunidad, esto nos lleva a un gran desafío ¿Cómo transformar esos conocimientos ancestrales en políticas públicas descolonizadoras? ¿Cómo esos conocimientos ancestrales en armonía con el conocimiento científico transforman los sistemas educativos actuales? ¿Cómo avanzamos un modelo de innovación intercultural desde el pluralismo epistemológico? Ante estas interrogantes hay que considerar lo que plantea Samanamud (2011) que las experiencias de las comunidades y el diálogo con los intelectuales indígenas son fundamentales para empezar el proceso de comprensión del buen vivir.

El cambio de paradigma es inminente, necesitamos diseñar, construir e implementar otra alternativa y el buen vivir puede ser una propuesta viable para transformar la sociedad y la recuperación de la Madre Naturaleza. El buen vivir es volver a la tierra, recuperar el sentido común, es la plenitud de la vida, es la alternativa del sistema en deterioro. Es vivir en equilibrio con la Madre Tierra y el Padre Cosmos, pone a la vida, la naturaleza y a las comunidades en el centro del debate sobre el camino a seguir, podemos construir un modelo de innovación intercultural para el diseño de políticas públicas, desde la visión del buen vivir para la humanidad y la vida en el planeta tierra.

\section{¿Época de cambios o cambio de época?: Implicaciones para el desarrollo de estrategias e innovaciones}

Los cambios de épocas no son una novedad para la humanidad; el último ocurrió hace cerca de 200 años cuando la Revolución Industrial condujo a la humanidad desde el agrarismo hacia el industrialismo, lo que generó incertidumbre, discontinuidad, inestabilidad, fragmentación, desorientación, inseguridad, perplejidad y por lo tanto, vulnerabilidad.

Parece que en la actualidad la humanidad experimenta, otra vez, la emergencia de una nueva época ¿Qué es una época histórica? ¿Cuándo cambia una época, y por qué las organizaciones de desarrollo se quedan vulnerables durante este fenómeno? Estas son preguntas fundamentales para comprender la génesis del actual cambio de época y la forma cómo este fenómeno aporta vulnerabilidad a todas las organizaciones 
de desarrollo. Esta comprensión será fundamental para inspirar estrategias innovadoras institucionales para la construcción de la sostenibilidad institucional.

La génesis del actual cambio de época está fuertemente asociada a tres revoluciones: La sociocultural, la económica y la tecnológica- cuyos impactos cruzados, que no necesariamente deben ser compatibles entre sí, están cambiando el sistema de ideas, de técnicas y la institucionalidad de la época histórica del industrialismo y están generando tres visiones del mundo en conflicto: las visiones mecánica, económica y holística-, las cuales se encuentran compitiendo entre sí para prevalecer en la época emergente.

Tabla 1. Visiones del mundo en conflicto en el contexto del cambio de época

\begin{tabular}{|c|c|c|c|}
\hline & V. Cibernética & V. Mercadológica & V. Contextual \\
\hline Metáfora & $\begin{array}{l}\text { El mundo es una máquina don- } \\
\text { de la importancia de todo es } \\
\text { reducida a información. }\end{array}$ & $\begin{array}{l}\text { El mundo es un mercado } \\
\text { donde la importancia de todo } \\
\text { es reducida a su función eco- } \\
\text { nómica. }\end{array}$ & $\begin{array}{l}\text { El mundo es una trama de } \\
\text { relaciones y significados entre } \\
\text { diferentes formas y modos de } \\
\text { vida. }\end{array}$ \\
\hline $\begin{array}{l}\text { Los seres } \\
\text { humanos }\end{array}$ & $\begin{array}{l}\text { Son "recursos humanos", piezas } \\
\text { del engranaje, porque todo } \\
\text { lo que entra en la máquina } \\
\text { es percibido como "recursos": } \\
\text { recursos naturales, recursos } \\
\text { financieros, recursos humanos, } \\
\text { etc. }\end{array}$ & $\begin{array}{l}\text { Son "capital humano" o "capi- } \\
\text { tal intelectual", porque todo } \\
\text { lo que entra en el mercado es } \\
\text { "capital”: capital natural, ca- } \\
\text { pital financiero, capital social, } \\
\text { capital humano, etc. }\end{array}$ & $\begin{array}{l}\text { Son "talentos humanos"; el } \\
\text { mundo tiene potencialida- } \\
\text { des naturales, humanas, etc. } \\
\text { Nuestra imaginación nos } \\
\text { permite crear más allá de la } \\
\text { experiencia actual y del cono- } \\
\text { cimiento previo. }\end{array}$ \\
\hline $\begin{array}{l}\text { Las orga- } \\
\text { ni- } \\
\text { zaciones }\end{array}$ & $\begin{array}{l}\text { Son "maquinas" innovadoras } \\
\text { que consumen, procesan y } \\
\text { producen información, que } \\
\text { es transformada en bienes y } \\
\text { servicios a ser ofertados. La } \\
\text { organización sostenible es la } \\
\text { organización eficiente, cuanto } \\
\text { mayor su grado de eficiencia } \\
\text { mayor su grado de sostenibili- } \\
\text { dad. La eficiencia productiva es } \\
\text { su objetivo. }\end{array}$ & $\begin{array}{l}\text { Son "proveedores" de bienes } \\
\text { y servicios demandados por } \\
\text { el mercado, que es la princi- } \\
\text { pal fuente de referencia para } \\
\text { la innovación. La organiza- } \\
\text { ción sostenible es la organi- } \\
\text { zación competitiva; cuanto } \\
\text { mayor su grado de competi- } \\
\text { tividad, mayor su sostenibili- } \\
\text { dad. La mayor competitividad } \\
\text { es su objetivo. }\end{array}$ & $\begin{array}{l}\text { Son "facilitadores de cambio". } \\
\text { inspiradas en los desafíos (ne- } \\
\text { cesidades, realidades y aspi- } \\
\text { raciones) del contexto donde } \\
\text { ocurre la aplicación e implica- } \\
\text { ciones de sus contribuciones. } \\
\text { La organización sostenible } \\
\text { es la organización cambiante } \\
\text { que innova y cambia junto } \\
\text { con su entorno cambiante. }\end{array}$ \\
\hline $\begin{array}{l}\text { Las } \\
\text { Innova- } \\
\text { ciones } \\
\text { relevantes }\end{array}$ & $\begin{array}{l}\text { Son "producidas" por organiza- } \\
\text { ciones de ciencia y tecnología, } \\
\text { que dependen de la inteligen- } \\
\text { cia y sensibilidad personal de } \\
\text { sus científicos. Para la "máquina } \\
\text { de innovar", la interacción es } \\
\text { innecesaria; los científicos } \\
\text { saben lo que es mejor para la } \\
\text { sociedad y el planeta. }\end{array}$ & $\begin{array}{l}\text { Son "proveídas" por organiza- } \\
\text { ciones de ciencia y tecnolo- } \\
\text { gía, que interpretan las seña- } \\
\text { les del mercado como la me- } \\
\text { jor fuente de inspiración. El } \\
\text { "proveedor de innovaciones" } \\
\text { interactúa con los "clientes" } \\
\text { para conocer sus "demandas", } \\
\text { pues estos son los únicos } \\
\text { actores relevantes. }\end{array}$ & $\begin{array}{l}\text { "emergen" de complejos pro- } \\
\text { cesos de interacción social, } \\
\text { con la participación de los } \\
\text { actores que las necesitan y } \\
\text { que son impactados por su } \\
\text { uso. La interacción social es } \\
\text { imprescindible: los "expertos" } \\
\text { que saben "cómo hacer" no } \\
\text { tienen el derecho de definir } \\
\text { solos "qué debe de ser hecho". }\end{array}$ \\
\hline
\end{tabular}

En este contexto complejo, cambiante, las organizaciones están en una posición que para cambiar o sobrevivir tendrán que innovar de una manera distinta. Si las "reglas del juego" del desarrollo están cambiando, igualmente las organizaciones de desarrollo tendrán que transformar sus "reglas del juego" institucional. De otra forma perderán sintonía y sostenibilidad. Por tanto, es necesario apuntalar las cosas diferentes a implementar modelos de innovación institucional más abiertos, donde se reconozcan otros conocimientos. 
Panorama general sobre las constituciones, educación superior y acceso de pueblos en Latinoamérica.

La influencia europea en la formación de los estados latinoamericanos generó por años la invisibilización de los pueblos indígenas en las legislaciones sin considerar que de acuerdo a datos de la CEPAL, en América Latina y el Caribe hay 826 pueblos indígenas que agrupan a más de 45 millones de personas, caracterizada por una enorme diversidad elementos que ha servido para importantes conquistas obtenidas a la fecha en la obtención de instrumentos jurídicos como el Convenio 169 sobre pueblos indígenas y tribales (OIT, 1989) y la Declaración Universal de Derechos de los Pueblos Indígenas (ONU, 2007).

Durante los últimos años estos instrumentos, han sido debatidos en distintos países lo que ha dado como resultado el reconocimiento del multiculturalismo en las Constituciones Políticas Nacionales de países como El Salvador (1983), Guatemala (1985), Colombia (1991), Paraguay (1992), Perú (1993), Panamá (1972 y 1994), Argentina (1994), Nicaragua (1987 y 1995), Guyana (1970 y 1996), Ecuador (1998), Honduras (1982 y 1999), Venezuela (1999), Costa Rica (1999), México (1992 y 2001), Brasil (1988 y 2002), Bolivia (1967 y 2004) y Chile (2009), estos cambios innovadores han dado como resultado el reconocimiento de la diversidad cultural y los derechos de los Pueblos Indígenas no así el de los Pueblos Afrodescendientes de América Latina, cuya invisibilidad todavía persiste (Cepal, 2014).

La creación de estos instrumentos innovadores a escala continental reconoce con mayor fuerza los derechos de los pueblos indígenas y se asemejan por la alta presencia o participación de las organizaciones indígenas, aunque sea sumisa en algunos casos en las asambleas nacionales constituyentes de cada país. En esta época de cambio, en donde las constituciones políticas reconocen la diversidad étnica, cultural y lingüística, casi ningún país ha incorporado aspectos sustanciales en sus legislaciones sobre las demandas de reconocimiento, inclusión y participación de los pueblos indígenas y afrodescendientes sobre la Educación Superior.

A pesar de ello, existe una diversidad de experiencias de Educación Superior en/con/para pueblos indígenas impulsadas por varios actores, esta diversidad de casos se ha implementado como producto de diversas modalidades de colaboración intercultural con los diversos actores antes mencionados.

Entre los diversos arreglos institucionales que se han dado dependiendo de cada contexto específico están la creación de Universidades e IES interculturales e indígenas, estas últimas caracterizadas por integrar conocimientos, saberes, prácticas, sueños y aspiraciones de los pueblos en armonía con el conocimiento "científico" como el caso de la URACCAN (Mato, 2018). En general estamos frente a un contexto diferente novedoso y de gran oportunidad, por lo que hay que avanzar en el marco conceptual e implementación de la Educación Superior Intercultural como proyecto político de vida de la región.

\section{Interculturalidad, colaboración intercultural}

Al finalizar la segunda década del XXI, el mundo actual está en un proceso de cambios acelerados, complejos cambiantes de muchos retos y oportunidades. Estos retos cobran mayor significancia en Latinoamérica si se considera la diversidad de pueblos en la región que la hacen rica en culturas, saberes, tradiciones, prácticas, valores étnicos y maneras diferentes de ver, interpretar y vivir del mundo (Hooker, 2018).

En las últimas décadas los pueblos demandan en agendas sus derechos, generando nuevos modos de relación institucional con diversos actores, una de las demandas es la descolonización de la educación, los avances se ven expresados en distintos instrumentos jurídicos internacionales expresados principalmente en el derecho a una educación realista, respeto a la diversidad e intercultural.

La región centroamericana cuenta con más de 200 universidades de las cuales sólo 22 (10\%) son públicas y unas 5 (2\%) se definen comunitarias, indígenas interculturales (Zúñiga, 2018). Este comportamiento de proliferación de universidades, así como el incremento de matrícula estudiantil es un comportamiento 
generalizado para toda Latinoamérica el reto sigue siendo que tanto programas y universidades sean contextualizadas con pertinencia cultural.

En este contexto la Educación Superior está en procesos de transformación universitaria. Así lo vislumbró la "Declaración Mundial sobre la Educación Superior para el siglo XXI", aprobada en París en 1998 cuando expresaban que las universidades debían emprender las reformas más radicales, porque todavía persisten desigualdades, discriminación, inequidades y el reconocimiento de las diversidades. Por tanto, las universidades son llamadas a desempeñar ese rol desde la interculturalidad. Pero, hablar de interculturalidad se hace desde distintas visiones que responden a contextos diferentes, desde experiencias e intereses diferentes por tanto es bueno reflexionar sobre ¿Qué entendemos por interculturalidad?

Hablar de interculturalidad, muchas veces se hace desde el discurso, sin realmente profundizar en los grandes desafíos que representa y es usada desde una diversidad de significados, pero ¿Desde dónde viene esta polisemia de la interculturalidad? Esta polisemia tiene su origen desde las mismas fuentes en distintos contextos creando a nivel global confusión, como el caso desde las sociedades anglosajonas vrs. Latinoamérica.

Dietz (2017, p. 192) plantea que, en "algunas sociedades, la interculturalidad se utiliza para referir a la diversidad provocada por la migración, mientras que en otras la misma noción se aplica para las interacciones entre pueblos indígenas y descendientes de colonizadores", la interculturalidad proviene de diversas fuentes en Latinoamérica, vemos que hemos tenido mucha influencia de la vertiente anglosajona centrada en el multiculturalismo que gestiona la diversidad para que esta deje de ser un problema asignando cuotas de participación a los pueblos, al final estas políticas tratan a las minorías para que sigan siendo minorías.

Mato (2009, p. 44), lo expresa como: “... un cierto tipo de mirada (a las relaciones) que puede aplicarse tanto al análisis de relaciones de colaboración, como de conflicto y que cualquier acción debe partir de reconocer que hay diversidad de contextos y por tanto de prácticas intelectuales y de saberes", a lo cual complementaría que se aseguren condiciones mínimas en igualdad de condiciones para dialogar.

\section{Colaboración intercultural "Es necesario empezar todo o casi todo"}

La innovación en los procesos de docencia, investigación y extensión - funciones sustantivas de las universidades - es una necesidad urgente y en la que los saberes ancestrales de los pueblos podrían contribuir - como principal fuente- a la creación de nuevos conocimientos. Históricamente Latinoamérica ha estado sometida a dolorosas y fuertes consecuencias por diversas visiones del mundo, lo que nos ha llevado a cuestionar en las universidades ¿Qué tipos de conocimiento producir, para qué y cómo? Las instituciones educativas insisten en enseñar contenidos descontextualizados, irrelevantes, poco utilizables, sin interrelación con la naturaleza y el cosmos. Sin embargo, lo que el mundo moderno necesita es una educación más pragmática, cuyos contenidos puedan utilizarse y aplicarse en la solución de los problemas que enfrentan los estudiantes, profesores y el liderazgo comunitario.

Si las universidades son la cuna o casa mayor del conocimiento donde se cultivan a los nuevos talentos que asumirán el bienestar de las sociedades, es necesario que aparte del entorno científico-académico, también conozcan sobre otras corrientes de saberes ancestrales a lo cual somos herederos.

La ciencia es más que producción es un diálogo socialcultural-natural porque todo está en la naturaleza, hemos caído en un estado de no cuestionar el paradigma tradicional occidental porque nos enseñaron a implementar recetas -reglas- para poder acceder al conocimiento científico, sin embargo, hay otras maneras de hacer ciencia e innovaciones donde no prevalece un solo saber, donde no solo los científicos son los grupos del saber. El problema es que cuanto los científicos nos volvemos arrogantes y poco permeables con otros sistemas de creencias, las sociedades toman otras alternativas irracionales muchas veces. 
Para ello la educación superior intercultural propone desarrollar formas de colaboración intercultural que parten del reconocimiento y valoración de las diferencias para la producción de conocimientos no exenta de problemas, conflictos y desafíos. La colaboración intercultural permite tomar en cuenta el aprendizaje situado en y por la práctica, importante para la transmisión y reproducción de conocimiento tradicionales, su recreación y generación de innovaciones, esto también es crucial para la apropiación de conocimiento.

La colaboración intercultural quiere decir establecer y sostener diálogos y relaciones interculturales de valoración y colaboración mutuas que sean de doble vía. Diálogos y formas de colaboración honestas y respetuosas, de interés recíproco, que partan de reconocer que hay diversidad de contextos y de prácticas intelectuales y de saberes (Mato, 2008). Producto de la colaboración intercultural han sido las Conferencia Regionales de Educación Superior (CRES, 1996), que orienta que la educación superior debía preservar y fortalecer la identidad cultural, la (CRES, 2008), mandata transformar estas universidades que sean pertinentes con la diversidad cultural, inclusión de cosmovisiones, conocimientos, saberes, practicas, sueños y aspiraciones y la (CRES, 2018), se ha permeado la interculturalidad y se ve mejor comprendido lo cual se refleja no sólo como un término sino como un eje temático. En general existe una tendencia a diseñar un Modelo de Universidad diferente, el actual ya no es pertinente, se requieren otras maneras de hacer docencia, investigación, extensión donde prevalezca la interculturalidad, colaboración intercultural y la innovación.

\section{La innovación desde un enfoque de interculturalidad}

De acuerdo a lo planteado por la CEPAL en el primer apartado sobre una América Latina caracterizada por una enorme diversidad, es necesario contar con un modelo amplio de simplemente sociedad del conocimiento, que sea útil para diseñar políticas y estrategias adecuadas para los países latinoamericanos en donde se aproveche la gran riqueza de conocimientos tradicionales, locales, autóctonos. Frente al concepto economicista podemos proponer otro según el cual una sociedad de conocimientos2:

es una donde sus miembros (individuales y colectivos) (a) tienen la capacidad de apropiarse de los conocimientos disponibles y generados en cualquier parte, (b) pueden aprovechar de la mejor manera los conocimientos de valor universal producidos históricamente, incluyendo los científicos y tecnológicos, pero también los conocimientos tradicionales, que en todos los continentes constituyen una enorme riqueza, y (c) pueden generar, por ellos mismos, los conocimientos que han falta para comprender mejor sus problemas (educativos, económicos, de salud, sociales, ambientales, etc.), para proponer soluciones y para realizar acciones para resolverlos efectivamente. (Olivé, 2009:20).

Desde este planteamiento, podríamos afirmar que la solución a las necesidades y problemas que enfrenta la sociedad debe basarse desde los principios de la participación efectiva de los actores involucrados en una sociedad de conocimientos. Si seguimos avanzando en este planteamiento entonces surge una inquietud ¿Quiénes deberían diseñar las políticas públicas entre ellas la de innovación y más aún en un contexto multicultural? ¿Qué modelo de sociedad de conocimientos necesitamos?

Un modelo de sociedades de conocimientos en un contexto como América Latina o para Nicaragua debería incluir por lo menos tres características que sea justas (mecanismos necesarios, satisfacer necesidades básicas, desarrollen capacidades y planes de vida de acuerdo a su cultura, democráticas (que las tomas de decisiones y las acciones se realicen mediante una participación efectiva de representantes legítimos de todos los grupos sociales involucrados y afectados en la formulación de los problemas y en las resoluciones para implementar soluciones) y plurales (que se reconozcan el valor de la diversidad cultural, así como respetar y fortalecer cada una de las culturas). Desde esta concepción, el modelo de sociedad intercultural reconoce la existencia de diferentes prácticas de innovación, entendida la innovación en un sentido amplio más allá que lo económico.

2 Olivé, L. (2009). "Por una auténtica interculturalidad basada en el reconocimiento de la pluralidad epistemológica“ 
En la literatura universal existen una gran cantidad de definiciones relacionadas con el concepto de innovación, la mayoría de ellas vinculadas con el impacto económico. Entre los principales exponentes de la literatura en materia de innovación es posible destacar a Shumpeter, como pionero en el uso del concepto aplicado a la economía y es a quien se le reconoce como el creador de la "Teoría de la innovación" y Peter Drucker, en nuestra época, se usa la planteada por la OCDE, en el "Manual de Oslo" y que se muestra a continuación.

Tabla 2. Definiciones en torno a la innovación

\begin{tabular}{|l|l|}
\hline \multicolumn{1}{|c|}{ Autor } & \multicolumn{1}{c|}{ Definición } \\
\hline Shumpeter: 1942 & $\begin{array}{l}\text { Introducción en el mercado de un nuevo bien o de una nueva clase de bie- } \\
\text { nes; de un nuevo método de producción aún no experimentado; la apertura } \\
\text { de un nuevo mercado de un país, tanto si el mercado existía como si no; la } \\
\text { adopción de una nueva fuente de suministro de materias primas o semi-ela- } \\
\text { borados tanto si existía (la fuente) como si no, y la implantación de una nue- } \\
\text { va estructura de mercado. }\end{array}$ \\
\hline Peter Drucker: 1977 & $\begin{array}{l}\text { Herramienta específica de los empresarios innovadores; el medio por el cual } \\
\text { explotar el cambio como una oportunidad para un negocio diferente. }\end{array}$ \\
\hline Manual de OSLO:2005 & $\begin{array}{l}\text { Es la introducción de un nuevo, o significativamente mejorado, producto } \\
\text { (bien o servicio), de un proceso, de un nuevo método de comercialización o } \\
\text { de un nuevo método organizativo, en las prácticas internas de la empresa, la } \\
\text { organización del lugar de trabajo o las relaciones exteriores. }\end{array}$ \\
\hline $\begin{array}{l}\text { URACCAN: 2019 } \\
\text { (Zúniga, 2019) }\end{array}$ & $\begin{array}{l}\text { la creación y recreación no sólo en nuevos productos, servicios y procesos, } \\
\text { sino también de nuevos conocimientos, saberes, prácticas, nuevas formas } \\
\text { de organización y modelos para resolver necesidades desde la creatividad, } \\
\text { diversidad, construcción colectiva y la perspectiva intercultural de género. }\end{array}$ \\
\hline
\end{tabular}

La última definición coincide con lo planteado por Olive sobre la innovación, la cual puede entenderse como:

El resultado de una compleja red donde interactúan diversos agentes, desde centros de investigación y universidades, empresas, agentes gubernamentales y estatales, hasta diferentes sectores sociales, incluyendo comunidades y pueblos indígenas, donde cada uno de ellos puede aportar una parte, pero donde el resultado no es sólo el agregado de sus contribuciones, sino las consecuencias de sus interacciones.

La innovación, desde este punto de vista, tiene que ver con la generación de nuevos conocimientos y ante todo con su aprovechamiento social para la resolución de problemas por parte de grupos específicos. Pero, desde luego no es necesario que se constituyan estas complejas redes. Una familia, comunidad puede ella misma realizar innovaciones que contribuyan a su desarrollo social.

El modelo de sociedad intercultural, debe llegar a plantear ciertos valores y normas que deben satisfacer y cumplir los diferentes grupos culturales, desde la condición de que están de acuerdo en convivir armoniosamente en una sociedad intercultural. Entre algunas que podríamos mencionar a la fecha es el respeto cultural, a la madre tierra, armonía de conocimientos (científicos-tecnológicos, locales, tradicionales, autóctonos), la espiritualidad, el diálogo de saberes-haceres-sentires, estas y otros son los elementos que se están construyendo para la comprensión de los problemas que enfrentan distintos grupos sociales, para que realicen las acciones que pueden solucionar esos problemas de manera colectiva con perspectiva intercultural de género. 
Si consideramos el carácter multiétnico y multicultural no sólo de América Latina sino de África, Asia y en la misma Europa, vemos que existe un enorme reservorio de conocimientos tradicionales, por lo cual todos los países, incluso los más "desarrollados", harían bien en revisar sus políticas de innovación con respecto al concepto de interculturalidad y a los conocimientos tradicionales.

La interculturalidad no debe ser entendida solamente dentro de los límites del reconocimiento fáctico de la existencia de una diversidad de culturas, es decir, aceptando la condición de multiculturalidad de las sociedades actuales, sino comprometiéndose en el análisis crítico hacia los fundamentos filosóficos que sostiene cada forma de entender el multiculturalismo, así como con sus implicaciones étnicas y políticas para el ejercicio efectivo de la interculturalidad.

Los conocimientos tradicionales - aquellos generados, preservados, aplicados y utilizados por comunidades y pueblos tradicionales, como los grupos indígenas de América Latina -, constituyen una parte medular de las culturas de dichos pueblos y tienen un enorme potencial para la comprensión y resolución de diferentes problemas.

Partiendo de estas características multiculturales de nuestra América Latina y en especial de Nicaragua, debemos apostar a un modelo intercultural, debemos avanzar hacia un concepto e implementación de la innovación intercultural incluyente de diferentes conocimientos, saberes, haceres y sentires: Todo esto mediante un trabajo interdisciplinario que nos permita tener nuevas ópticas de la innovación.

\section{La experiencia innovadora de la URACCAN}

La universidad de las Regiones Autónomas de la Costa Caribe Nicaragüense (URACCAN), es una universidad novedosa, se autodefine como: comunitaria intercultural creada por un grupo de hombres y mujeres líderes indígenas, afrodescendientes y mestizos costeños de las Regiones Autónomas para ejercer el ejercicio pleno del derecho de los pueblos a una educación superior. Su carácter comunitario está determinado en el acompañamiento de los procesos de autogestión comunitaria para la profundización de la autonomía en la diversidad.

En la URACCAN la interculturalidad es concebida como un proceso permanente de construcción, establecimiento y fortalecimiento de espacios de diálogo, comunicación e interacción horizontal de doble vía, entre personas, comunidades y pueblos de diferentes culturas, también comprendida como el desarrollo de procesos de toma de decisiones conjuntas en igualdad de condiciones; su finalidad es la promoción y práctica de la equidad, el respeto, la comprensión, aceptación mutua y creación de sinergias para el establecimiento de sociedades inclusivas, no discriminatorias y libres de racismo (URACCAN, 2015).

Algunas innovaciones realizadas con y para los pueblos indígenas, afrodescendientes y comunidades étnicas son los Modelos de Salud y Educación Autonómicos Interculturales, indicadores de autoevaluación para universidades interculturales, el modelo de universidad comunitaria intercultural, etc. Estas innovaciones con pertinencia cultural han tenido como base la creatividad, la diversidad, colaboración, diálogo de saberes-haceres y sentires, armonía entre conocimientos científico-ancestral, participación, la espiritualidad y la perspectiva intercultural de género, lo que ha permitido diseñar propuestas justas, democráticas y plurales.

\section{Conclusiones}

Estamos ante un contexto cambiante, complejo; pero, de muchas oportunidades, en una época de cambios se requiere de organizaciones e instituciones preparadas para su sostenibilidad. La gestión de modelos de innovación puede aportar mucho a esa sostenibilidad, por tanto se requiere urgentemente profundizar en el estudio de un nuevo modelo de innovación intercultural que considere la diversidad cultural de nuestras sociedades, desde el pluralismo epistemológico que considere más allá que simplemente lo económico o centrado en un solo conocimiento hegemónico, sino un modelo de innovación intercultural que considere 
todos los tipos de conocimientos en contextos multiculturales dirigido al desarrollo de capacidades y creación de condiciones que propicien la construcción de una sociedad de conocimientos justa, democrática y plural.

\section{Agradecimiento}

Esta publicación obtuvo el financiamiento de: El Fondo de Asistencia Internacional de los Estudiantes y Académicos Noruegos (SAIH).

\section{Lista de referencias}

Acosta, A. (2008). El buen vivir, una oportunidad por construir. Revista Ecuador Debate. Centro Andino de Acción Popular.

CEPAL (2014). Los pueblos indígenas en América Latina. Avances en el último decenio y retos pendientes para la garantía de sus derechos. 1a ed., Santiago de Chile, ONU.

CRES (1996). I Conferencia Regional sobre Politicas y Estrategias para la Transformación de la Educación Superior en América Latina y el Caribe. Centro Regional para la Educación Superior de la República de Cuba. (CRESALD, ahora IESAL).

CRES (2008). Declaración y Plan de acción de la Conferencia Regional de Educación Superior en América Latina y el Caribe. Organización de las Naciones Unidas para la Educación la Ciencia y la Cultura. Instituto Internacional de la UNESCO.

CRES (2018). Declaración de la III Conferencia Regional de Educación Superior para América Latina y el Caribe. Organización de las Naciones Unidas para la Educación la Ciencia y la Cultura. Instituto Internacional de la UNESCO.

Dietz (2017). Interculturalidad: una aproximación antropológica. Revista Perfiles Educativos. Vol. XXXIX. Núm. 156, 2017. (p. 192-207). Editorial Alejandro Márquez Jiménez. México.

Drucker, Peter (1977). El empresario de la nueva era: Diálogos en Pomona. Ed. CECSA, México.

Escobar, A. (2005). El "postdesarrollo" como concepto y práctica social. En Daniel Mato (coord.). Políticas de economía, ambiente y sociedad. Caracas: Facultad de Ciencias Económicas y Sociales, Universidad Central de Venezuela, pp. 17-31.

Galbraith, J.K. (1994). Un viaje por la economía de nuestro tiempo. Ariel Barcelona.

Hooker, A. (2018). Universidades e instituciones de educación superior indígenas, interculturales, afrodescendientes y comunitarias en América Latina. En: Daniel Mato, coord. Educación superior, diversidad cultural e intercultural en América Latina. Págs.: 299 - 321. Editoriales: UNESCO-IESALC y UNC.

Mato, Daniel (2018). Educación Superior y Pueblos Indígenas: Experiencias, estudios y debates en América Latina. Revista Cisen Tramas/Maepova, 6 (2), (Págs.: 41 - 65).

Mato, Daniel (2009). Contextos, conceptualizaciones y usos de la idea de interculturalidad. En: Miguel Aguilar, Eduardo Nivón, María Portal, Rosalía Winocur, coord....Pensar lo contemporáneo. (Págs.:28 - 50). Anthropos Editorial. Barcelona, España.

Mato, Daniel (2008). No hay saber "universal", la colaboración intercultural es imprescindible. ALTERIDDES, 2008, 18 (35). (Pág.: $101-116)$. 
Naciones Unidas. (2007). United Nations declaration on the rights of indigenous peoples.

OCDE (2005). Manual de Oslo, Guía para la recogida e interpretación de datos sobre innovación. Tercera edición, 2005, Traducción española: 2006, en internet: http://www.conacyt.gob.sv/Indicadores\%20 Sector\%20Academico/Manual de Oslo\%2005.pdf

OIT (1989). Convenio 169 sobre pueblos indígenas y tribales.

Olivé, L. (2012). "Por una auténtica interculturalidad basada en el reconocimiento de la pluralidad epistemológica” en Pluralismo Epistemológico. Luis Tapia Mealla (coord.), CLACSO, CIDES-Universidad Mauor de San Andrés, La Paz, Bolivia.

Samanamud, A. (2011). Es un error reducir el Vivir Bien/buen vivir a un paradigma. Seminario buen vivir, Desarrollo y Post-desarrollo. http://www.fedaeps.org/cambio-civilizatorio-y-buen-vivir/ samanamud-es-un-error-reducir-el

Santos, B. (2002). Towards a New Legal Common Sense. Londres: Butterworth.

Shumpeter, J. (1942). Capitalism, socialism \& Democracy. USA; ED. ROUTLEDGE, ISBN o-415-10762-8, 1942.

Unceta, K. (2009). Desarrollo, subdesarrollo, maldesarrollo y postdesarrollo. Una mirada transdisciplinar sobre el debate y sus implicaciones. Carta Latinoamericana.

UNESCO. (1998). Declaración Mundial sobre la Educación Superior en el siglo XXI: Visión y Acción. Conferencia Mundial Educación Superior. Paris, Francia, octubre de 1988.

UNESCO, IESALC. (2006). Informe Educación Superior en América Latina y el Caribe. 2000 - 2005. La metamorfosis de la educación superior. Primera edición. Caracas.

URACCAN (2016). Perfil institucional. URACCAN: Universidad Comunitaria Intercultural. Universidad de las Regiones Autónomas de la Costa Caribe Nicaragüense. Managua.

Zúniga, V. (2019). Visiones de la Innovación. "Hacia un modelo de innovación intercultural". Documento borrador. URACCAN. Managua.

Zúñiga, Xinia (2018). Persistencias coloniales, aperturas y desafíos para la educación superior en Centroamérica. En: Daniel Mato, coor. Educación Superior, Diversidad Cultural e Interculturalidad. Págs.:117 - 142. Editoriales: UNESCO-IESALC y UNC. Impreso en Argentina por la Universidad Nacional de Córdoba (UNC). 